Research Article

\title{
Application of Artificial Intelligence and Collaborative Knowledge for Manufacturing Design
}

\author{
Tingting Luo $\mathbb{D}$, ${ }^{1}$ Guangyao $\mathrm{Li} \mathbb{( \mathbb { D } )}{ }^{1}$ and Naijiang $\mathrm{Yu} \mathbb{D}^{2}$ \\ ${ }^{1}$ School of Electronics and Information Engineering, Department of Computer Science and Engineering, Tongji University, \\ Shanghai 20184, China \\ ${ }^{2}$ China Aviation Commercial Aviation Engine Co. Ltd. Design ReD Center, Shanghai 200241, China \\ Correspondence should be addressed to Tingting Luo; ltt_edu@outlook.com
}

Received 14 September 2021; Revised 2 November 2021; Accepted 13 November 2021; Published 9 December 2021

Academic Editor: Rahman Ali

Copyright (c) 2021 Tingting Luo et al. This is an open access article distributed under the Creative Commons Attribution License, which permits unrestricted use, distribution, and reproduction in any medium, provided the original work is properly cited.

With the rapid development of science and technology, digital technology has brought the world economy and management into a new stage. Collaborative design can realize product design process by cross-regional and cross-industry designers and share and exchange product information through network. With the rapid development of big data and artificial intelligence, knowledge services have gradually developed into multirole collaborative design activities based on artificial intelligence decision support. Traditional manufacturing industry has gradually transformed into modern manufacturing service industry after integrating information technology means such as Internet, communication, computer, and modern management methods. This article focuses on artificial intelligence decision support systems and the complex product manufacturing industry. We present a detailed analysis of how to integrate the knowledge generated by the product life cycle in the era of big data. We calculate the influence coefficient and sensitivity index of four different industries and propose a metadata architecture to improve the value of products as a whole. The findings of the research study imply that a knowledge-based collaborative platform should be designed by the enterprises and industries and a platform-based construction approach for economical, practical, and reliable production. We also present a detailed discussion about other factors such as the network cost of symmetric services, raw data and forecast data, and the number of nodes and the processing complexity.

\section{Introduction}

-In the 21st century, science and technology are developing rapidly, especially artificial intelligence and big data technology due to the digitization of the industries and the advancement of the Internet, which brings the economy and management of today's world into a completely new stage [1]. The task of process planning is often accomplished by a group of experts with different domain knowledge distributed in different process design departments, because of the progress in the fields of information technology, especially the rapid development of computer and communication technology [2]. In the network environment, according to specific development resources and constraints, the simulation of interdisciplinary expert cooperation in the development of natural attributes with network coordination functions has always been a hot issue in the field of mechanical design and manufacturing [3]. Collaborative design based on artificial intelligence decision support system enables the product design process to be coordinated by designers across regions and industries and to share and exchange product information through the network [4], thereby achieving the purpose of improving design capability, reducing product development costs, and shortening product development time.

The manufacturing industry plays an important role in promoting the development of the national economy, meeting basic needs, absorbing the employed population, expanding foreign trade, and promoting technological innovation [5]. After the integration of the Internet, communications, computers and other information-based means and modern management methods, the traditional 
manufacturing industry has gradually transformed into a modern manufacturing service industry. The manufacturing method has gradually evolved from large-scale production line to personalized, customized, and digital [6]. Artificial intelligence and big data knowledge services are gradually becoming a new service growth point in the manufacturing sector. China's manufacturing industry's industrial structure level, innovation capability, overall quality, and competitiveness are obviously behind the developed countries and are at the low end of the global value chain [7]. Service industry will be the great potential of future economic growth, and the trend of replacing traditional technology service mode with high-tech and practical public information knowledge as the main content of technical services is becoming more and more obvious [8]. With the rapid development of big data and manufacturing industry, knowledge services have gradually developed into multirole collaborative design activities. From the total amount of resources and energy, the per capita share of resources in China is far below the world average, and the environmental carrying capacity is weak [9]. According to the requirement of product manufacturing process design, it is of great theoretical value and practical significance to explore the mode and application method of distributed manufacturing process collaborative design.

With the development of communication technology, the coverage of computer network is expanding constantly, the transmission rate of network is increasing continuously, and the application of network is also developing continuously [10]. The transformation to a new technology service mode has become an important strategic component of manufacturing industry [11]. It is not only the potential value of manufacturing industry, but also the powerful pillar of technological innovation and enterprise value added. The implementation technology of collaborative product development process management system in networked manufacturing environment is presented [12]. But they have not applied the modeling and management model to the field of product manufacturing process design. There are significant gaps between China's manufacturing enterprises in terms of independent innovation capability, resource utilization rate, and quality and other technical capabilities compared with developed countries [13]. Stepping out of the constraints of traditional manufacturing technology service thinking, the technical service model will be transferred to a more convenient and superior network environment, giving full play to the enormous intangible value of knowledge management theory [14]. It is the inevitable way out for the development of manufacturing technology services. This article analyzes artificial intelligence decision support systems and focuses on the complex product manufacturing industry and the integration of the knowledge generated by the product life cycle in the era of big data. The analysis and application of the knowledge big data formed after integration is taken into account, and the impact of product life cycle on resource consumption and environment is considered in the design stage. The aim is to help design and develop complex product lifecycle design, big data integration, and application systems.

\section{Materials and Methods}

Artificial intelligence (AI) has the ability to provide autonomy and flexibility in a dynamic and multistandard decision-making environment. Artificial intelligence enables organizations and researchers to make intelligent decisions because its integration with operations research will enhance the capabilities of DSS. Manufacturing design collaborative and application of knowledge based on artificial intelligence decision support will play a huge role in promoting the development of the industry.

Through the big data network environment, the knowledge service life cycle process can provide all kinds of knowledge service activities such as access, on-demand use and payment, security and credibility, and green quality. There are four streams that determine the diffusion process of the extension manufacturing capability unit, that is, resource flow, knowledge flow, capability flow, and quality flow. The combination of these four streams enables large engineering equipment manufacturing systems to emerge in a short period of time with rapid expansion of manufacturing capabilities. Figure 1 is a model of an extension manufacturing capability unit.

Taking the design of mechanical products as an example, it is necessary to consider the design process in parallel, in a comprehensive manner from the aspects of product function, appearance, processing technology, production cost, market demand, quality control, and reusability. Passive technology services proactively seek help from technology providers when products or technology users encounter problems during the product lifecycle [15]. In the design process of the product, it involves the knowledge or expertise of the fields related to the product and also involves the comprehensive processing and utilization of these multidomain knowledge, experience, and data. Small and microenterprises in manufacturing have more difficulties in transforming scientific and technological achievements into applicability [1]. The results of cooperation are often difficult to determine, and the interests of all parties involved in cooperation are difficult to be guaranteed. Supported by effective network, it realizes efficient collaborative design, improves design quality, and shortens product development and manufacturing cycle. An important issue of collaborative management of manufacturing large data knowledge service system is to make in-depth analysis of the large data contained in manufacturing industry. After sorting out the original input-output tables, the input-output tables of departments are compiled. According to this classification and the calculation formula of the influence coefficient and the stress coefficient, the influence coefficient and the sensitivity coefficient of the four industries can be obtained, as shown in Table 1.

The base platform provides an open technical architecture, including authentication services, log services, data services, workflow services, reporting services, and customized services [16]. An intelligent Web digital image information retrieval platform using dynamic XML documents to support intelligent image retrieval is proposed. 


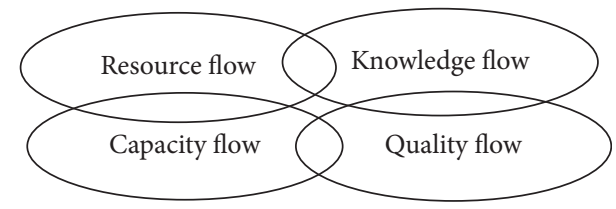

Figure 1: Extension manufacturing capability unit model.

TABLE 1: Industry influence coefficient and sensitivity index.

\begin{tabular}{lcc}
\hline Industry type & Influence & Sensitivity \\
\hline Industry & 4.569 & 15.212 \\
Agriculture & 12.756 & 18.369 \\
Service industry & 7.372 & 9.322 \\
High-tech industry & 8.644 & 11.374 \\
\hline
\end{tabular}

In engineering design, not only rich professional knowledge and design basic data but also the practical experience of experts is needed. Through the analysis and prediction of data, the traditional way of relying on intuition, fuzzy judgment, etc., will gradually be replaced. At the macrolevel, research on technological capabilities focuses on the main players in developing countries. The main research focus is to make these countries introduce technology from developed countries. Learning, absorbing, and digesting the advanced technology introduced into it transforms it into the technological capabilities of its own country. The development of the product life cycle is inseparable from synergy [17]. After the discussion of the various process system solutions is reached, the process plan verification module is submitted to the program for confirmation. After the scheme is confirmed, the boundary constraints discussed by each system will come into effect, and each process system will formulate its own process specifications according to the constraints. Design is an innovative and a knowledge-based computing process. It requires not only knowledge and expertise in different fields, but also an effective mechanism for synthesizing and coordinating these expertise.

To improve the value of products as a whole, new product development of enterprises must pay attention to the importance of teamwork. With the help of the basic platform, the existing application systems and resources can be integrated, so that product-related personnel can access the required product data at anytime and anywhere. Since the application of computer and information technology in molecular biology research, tens of thousands of data sources have been generated in a short time. Storage structure is designed by considering the mapping relationship between XML documents. Metadata architecture is shown in Figure 2.

The essence of managing a company from a strategic perspective is to attach importance to the reserve of technological capabilities. The most critical resource and wealth of an enterprise is its ability. The competition for new knowledge based on knowledge will inevitably require the birth of new design methods and means to achieve computer-aided design in the true sense, rather than just replacing the drawing board with a computer [18]. The real resources within the enterprise are the controllable resources of the enterprise, but the large amount of virtual resources within the enterprise is uncontrollable, such as employees' intellectual resources, technical resources, and related resources. Extenics has made a general expansion of the definition of resources. It believes that all sources of force that can exert an effort on an organization can be called resources of the organization. The random consistency ratio data is shown in Table 2.

There are $n$ indicators for evaluating the independent innovation capability of enterprises. Based on this part of the indicators, the independent innovation capability of enterprises is quantitatively divided into $T$ grades, which are described as the following quantitative comprehensive evaluation matter-element models:

$$
Q\left(u_{i j}\right)=\sum_{i=1}^{n} \underset{1 \leq j \leq m}{\operatorname{Max}}\left\{g_{i j}(T)\right\}
$$

The matter-element model formed by the comprehensive evaluation of the independent innovation ability and the allowable value range of each indicator is called the domain matter element:

$$
y_{f-n_{m}}=\sum_{i=1, i \neq n}^{N} \sum_{l=1}^{M} \sqrt{p_{i_{l}}} h_{i, n_{m}}^{T} W_{i, i_{l}} s_{i_{l}} .
$$

For the enterprise to be evaluated, the data or analysis result obtained by the evaluation is represented by the matter element $P$ :

$$
d=2 r_{b}\left(\frac{\sqrt{2} \sigma_{R} B}{2 \sigma_{t d}}\right)^{1 / \beta}\left(\frac{\sqrt{2} \rho_{0} D^{2} n k^{-2 \gamma} l_{e} B}{16 \sigma_{c d}}\right)^{1 / \alpha} .
$$

The proposed big data knowledge service model provides new solutions, ideas, and ways to solve the problem of integration of big data and manufacturing. Proactively provide technical support or guidance to product users, and the technical service process is mainly based on the reuse of technical service knowledge. A complex manufacturing process can often be broken down into several parts according to the type of process, which is consistent with the characteristics of discrete manufacturing in actual processing [16]. The new WEB information publishing framework based on XML is more adapted to the development of information society, which makes the site obtain very flexible extensibility. Secondly, it helps website builders to reduce labor costs. For online computing and e-mail service software, users must also set its operating parameters. They are related to the interface design of software input parameters and the correct operation of software. With the increasing complexity of the system, the cost of operation and maintenance of Web applications requires higher and higher ability of operation and maintenance personnel.

The main asset of knowledgeable and skillful knowledge is intangible assets. The development of enterprises depends on the importance and investment of intangible assets. How can low-tech enterprises become their own technological capabilities by introducing advanced technological knowledge and learning, absorbing, and digesting it, and ultimately transforming it into their own independent 


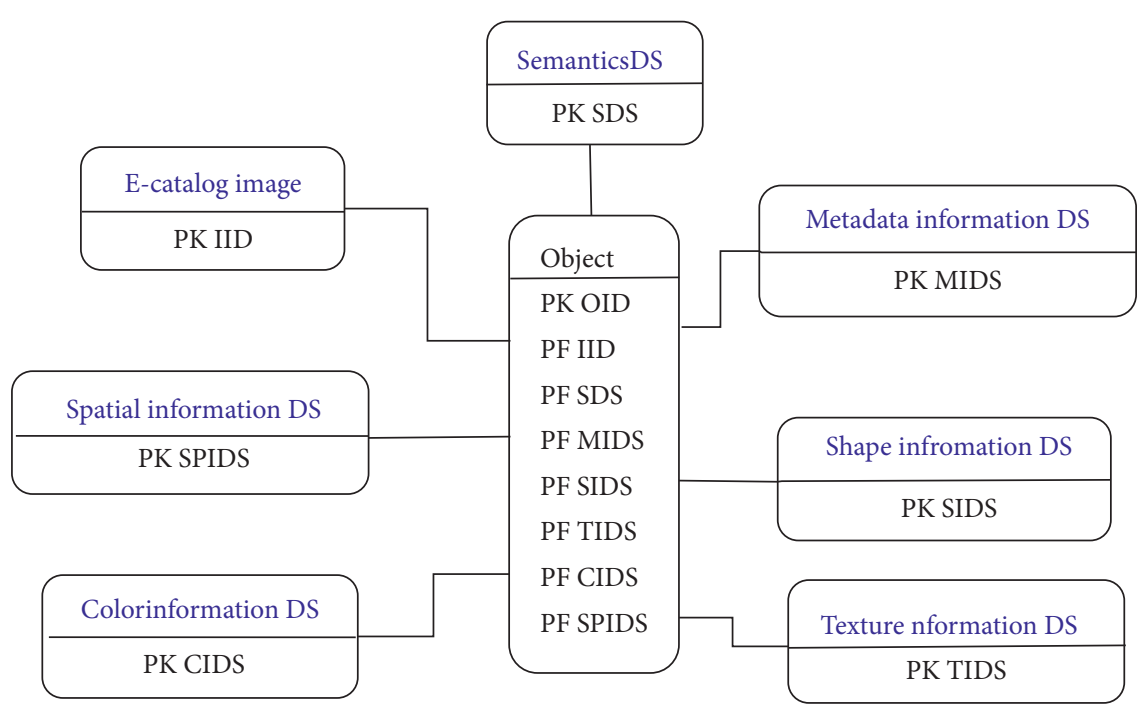

FIGURE 2: Metadata architecture.

TABle 2: Random consistency ratio data.

\begin{tabular}{lccccccc}
\hline$n$ & 1 & 2 & 3 & 4 & 5 & 6 \\
\hline Random consistency ratio & 0.21 & 0.31 & 0.68 & 0.79 & 1.02 & 1.57 & 1.36 \\
\hline
\end{tabular}

innovation capabilities? Technological progress is an important way to change the appearance of enterprise production and provide economic benefits. Service centers are connected with many related resources to form resources in the repository for use. According to the project requirements, the resources are optimized. The project is passed to the relevant resource provider, and the resource provider completes the related service. When all systems complete their respective process design tasks in accordance with the constraints, a complete manufacturing process specification is formed. The specification is finally a formal process through auditing and verification. A knowledge-based collaborative design platform should be an ideal choice, and a platform-based construction approach is economical, practical, and reliable.

\section{Result Analysis and Discussion}

After establishing the index system of venture capital in target industry, the analytic hierarchy process (AHP) can be used to evaluate the project risk comprehensively. Comparing the same grade index, according to the relative importance of the index, the scale score is given. The weight judgment matrix is constructed. According to the sample data, the weights and evaluation values are obtained.

Due to the proliferation of data from different systems, devices, and applications, it is becoming more and more difficult to collect, analyze, and interpret these data in a short time based on traditional data processing software. Most of the information interaction work is in the data transfer interface module. Here, we must complete the organization and transmission of various process data. It mainly uses various input and output commands defined by the program call interface to realize the acquisition and expression of process data [19]. More and more companies are analyzing and applying the large amount of data generated by enterprises, gaining competitive advantages and making them invincible in an increasingly fierce market environment. In the process of collaborative design, in order to coordinate the work of each system, the information symmetry between the systems should be maintained, that is, the information synchronization between the systems is maintained. Applied research mostly uses applied economic methods, theories, models, and statistical analysis tools. The evaluation index system of competitiveness is constructed, and the performance of enterprise competitiveness is evaluated and analyzed through empirical analysis. Technological providers can save costs and also gain benefits. In addition, the system itself has also been updated with technical service information or knowledge.

Considering the symmetrical demand for large data, when the relative bandwidth demand for network capacity is relatively large, the symmetrical traffic demand will be treeshaped. When traffic demand is lower, the total cost of calculation increases linearly because of different traffic demands, routing has not changed, it is a kind of tree routing, and only the reserved bandwidth of each link is changed. The corresponding parameters for different business items are shown in Table 3.

A node with a large compactness may not have a large degree value, but it plays a very important role in data transmission. The degree of some nodes is not very large, but their parameters are relatively large. It reflects the core degree of these nodes in the network. If these nodes are deliberately attacked, the whole network may be paralyzed. 
TABLE 3: Network cost of symmetric services.

\begin{tabular}{lccccc}
\hline Business type & 1 & 2 & 3 & 4 & 5 \\
\hline TDR & 25.007 & 34.386 & 26.842 & 18.556 & 25.007 \\
Single domain & 36.318 & 35.278 & 23.876 & 22.374 & 26.316 \\
Hybrid & 21.505 & 43.609 & 15.619 & 25.824 & 31.504 \\
\hline
\end{tabular}

For example, Table 4 shows the data between nodes, tightness, and parameters.

Any enterprise that faces huge user data needs to find data that suits its own development characteristics. Get real feedback from users to ensure that the company has good economic benefits. Each communication circuit set must pass as few communication nodes as possible in order to increase the compactness of the topology.

The strategic implication of industrial big data is not how much data the enterprise has, but how to analyze, interpret, and apply the data and professional processing to achieve value-added data. After the configuration is completed, the data analysis is run. The number of information nodes used in each analysis is different, and the corresponding processing time is also different. Table 5 shows the number of nodes and processing time for each analysis.

When the display format is important, we can specify how to display the data. Finding the optimal solution set makes each objective function as large or small as possible. In the actual application process, the algorithm is as follows:

$$
k_{i}=A_{i} \exp \left(\frac{-\Delta E_{i}}{R T}\right) .
$$

When we need to establish a database connection in your program, we only need to take one from the memory instead of rebuilding a connection. Discuss this issue, and the mutual formula is as follows:

$$
q_{f}=-\frac{\mathrm{d} p-R_{f}}{\mathrm{~d} x} .
$$

If the linear system should be processed well, then the minimized problem can be handled in the following method:

$$
\begin{aligned}
& \operatorname{Dr}(p)=\frac{D(p)}{\min \left(P_{A}, P_{B}\right)}, \\
& R_{A}(p)=\frac{\min \left(A_{A}, A_{B}\right)}{\max \left(A_{A}, A_{B}\right)} .
\end{aligned}
$$

This algorithm can choose the adaptive nearest neighbor algorithm:

$$
\operatorname{Cost}\left(P_{i}\right)=\sum_{e \in P_{i}} C(e)
$$

In the implementation, modules with strong cohesiveness and low coupling with other tasks can be separated to form a collaborative task. Doing so reduces boundary constraints and makes it easier to start the next phase of the task. Since the parallel design of concurrent engineering is divided into intergroup and intragroup collaboration, the work of members in the group is closely linked, and the coordination is generally required to be synchronized. The
TABLE 4: Data between nodes, tightness, and parameters.

\begin{tabular}{lccc}
\hline & Node degree & Tightness & Node parameter \\
\hline Node degree & 1 & 0.86 & 0.42 \\
Tightness & 0.68 & 1 & 0.67 \\
Node parameter & 0.74 & 0.69 & 1 \\
\hline
\end{tabular}

TABLE 5: Number of nodes and processing time.

\begin{tabular}{lcc}
\hline Cycle & Number of nodes & Processing time \\
\hline 1 & 33500 & 1800 \\
2 & 34700 & 2400 \\
3 & 38900 & 3600 \\
4 & 39200 & 3700 \\
\hline
\end{tabular}

design work between groups may take some time to collaborate, so the collaboration can be done asynchronously. Core competencies can have an important impact on the customer value of the final product and service. It can bring the core benefits of the customer's attention, not just the short-term general benefits [20]. In the process of project execution, workflow provides process monitoring tools to facilitate managers at all levels to understand the progress and status of work. This can relatively reduce the difficulty of the task and speed up the completion of the task. The concurrent engineering oriented collaborative design system should provide enough facilities to form a collaborative environment. It enables collaborative participants to use facilities in the environment to describe collaborative requirements. The system is customized so that the system has the collaborative support facilities needed by users.

The selected indicators should cover as much as possible the content of the evaluation, which can fully reflect all aspects of the enterprise's independent innovation capability, and have good representativeness. Similarly, the correlation value of each grade index can be obtained, as shown in Table 6.

In a network with $h$ nodes, the sum of the distances of nodes to other nodes is generally not lower than $h-1$, and then, the normalized compactness index $P_{h}$ is defined as

$$
P_{h}=\frac{\sum_{i=1}^{h} \sigma_{i}^{2}}{\sum_{i=1}^{m} \sigma_{i}^{2}}
$$

A data point is defined as the minimum of the distance from point $k$ to any point with a higher local density point:

$$
U_{i j}=\frac{H_{i j}}{\sqrt{\sum_{t=1}^{k} H_{i t}^{2}}}, \quad i=1, \ldots, n, j=1, \ldots, k .
$$

Update the speed and position according to the following formula:

$$
K_{i}=\frac{t * \operatorname{sqrt}(N e)+\alpha}{L+\beta}
$$

The inertia weight still decreases linearly with the increase of the number of iterations, which effectively improves the search accuracy and convergence ability. The update formula is as follows: 
TABLE 6: Value of relevance function of evaluation level.

\begin{tabular}{lcccc}
\hline Grade indicator & 1 & 2 & 3 & 4 \\
\hline A1 & 0.452 & 0.356 & 0.928 & 0.423 \\
A2 & 0.537 & 0.782 & 0.199 & 0.398 \\
A3 & 1.085 & 0.954 & 1.312 & 0.781 \\
A4 & 0.342 & 0.438 & 0.715 & 0.711 \\
\hline
\end{tabular}

$$
Q\left(u_{i j}\right)=\sum_{i=1}^{n} \operatorname{Max}_{1 \leq j \leq m}\left\{g_{i j}(T)\right\} .
$$

The collaborative technology service module mainly realizes the instant assignment and supervision feedback of the expert group technical service coordination, enterpriselevel technical service coordination, and technical service tasks. It can be done centrally by an experienced team, and the task tends to end when it starts. Because the data center network is relatively closed and the management is relatively concentrated, it is subject to different performance requirements in the actual deployment process and presents a situation in which multiple network forms coexist. Meet the premise of cointegration test. Test for long-term equilibrium relationships between related variables. The test results are shown in Table 7.

Effective computer support for collaborative work does not necessarily require very detailed and accurate modeling of the actual work context. The behavior of the collaborative system should be customized by the user to meet the needs of openness and flexibility. The core competitiveness is the unique ability that the company has formed in the course of its operations that is not easily emulated by competitors and can bring excess profits. In the implementation of the workflow, the enterprise's personalized process requirements are also considered, and the process control logic is extended to better meet the flexibility of the process definition. The management function module is mainly used as a module for platform management and maintenance, which implements user management, data management, resource management, business management, and other extended functions [21]. In order to ensure the synchronization of information and smooth information and enhance the maintainability of the integrated system, a message management module is established and implemented by COM technology. With the rapid development of computer network technology and the deepening of concurrent engineering theory and practice, the integration of concurrent engineering and computer-supported collaborative work will be one of the effective means for the implementation of concurrent engineering, and it is also an inevitable trend for the research and development of concurrent engineering theory. When using big data, we should not only pay attention to internal data, but also to external data. Through the accumulation of knowledge learning and technological capabilities, enterprises can develop their own core competencies through market competition.
TABLE 7: Cointegration test results.

\begin{tabular}{lcc}
\hline Eigenvalues & Trace estimate & Threshold \\
\hline 0.842 & 1108 & 139.8 \\
0.715 & 965 & 142.1 \\
0.963 & 1271 & 159.4 \\
0.347 & 946 & 188.5 \\
\hline
\end{tabular}

\section{Conclusions}

With the rapid development of economic globalization and big data technology, product manufacturing process will become a very complex and data-intensive process. Effective integration of product design, manufacturing, supply, inventory, sales, and management decision-making is needed. Technical service platform is the aggregation of technical resources, which integrates various technical knowledge information, human resources, and technical business resources. Computer collaborative design is an interdisciplinary subject which combines the collaborative theory of computer science with mechanical design. It involves a wide range of knowledge fields. There are many fields in manufacturing industry. According to their fields, manufacturing enterprises have different industry characteristics and enterprise characteristics. No theoretical approach can be applied to the innovation activities of all manufacturing companies. A resource management module needs to be established to rationally plan these decentralized heterogeneous resources. System process messages, or asynchronous messages, are used to implement real-time communication for each user in a collaborative system. The advantage of the public database approach based on the unified product model is that information can be shared smoothly and in real time between functions. Knowledge big data formed through knowledge integration makes the knowledge in the enterprise knowledge base rich and perfect. Help companies better use the value of knowledge big data.

\section{Data Availability}

Data sharing is not applicable to this article as no datasets were generated or analyzed during the current study.

\section{Conflicts of Interest}

The authors declare no potential conflicts of interest with respect to the research, authorship, and/or publication of this article.

\section{References}

[1] A. Kusiak, "Smart manufacturing must embrace big data," Nature, vol. 544, no. 7648, pp. 23-25, 2017.

[2] R. Y. Zhong, C. Xu, C. Chen, and G. Q. Huang, "Big data analytics for physical internet-based intelligent manufacturing shop floors," International Journal of Production Research, vol. 55, no. 9, pp. 2610-2621, 2017. 
[3] Y. Xu, G. Chen, and J. Zheng, "An integrated solution-KAGFM for mass customization in customeroriented product design under cloud manufacturing environment," International Journal of Advanced Manufacturing Technology, vol. 84, no. 1-4, pp. 85-101, 2016.

[4] S. K. Hyoung, Y. L. Ju, C. SangSu et al., "Smart manufacturing: past research, present findings, and future directions," International Journal of Precision Engineering and Manufacturing-Green Technology, vol. 3, no. 1, pp. 111-128, 2016.

[5] D. Dutta and I. Bose, "Managing a big data project: the case of ramco cements limited," International Journal of Production Economics, vol. 165, pp. 293-306, 2015.

[6] Z. T. Li, H. Yanga, S. Zhangb, and L. Guosheng, "Unrelated parallel machine scheduling problem with energy and tardiness cost," International Journal of Advanced Manufacturing Technology, vol. 84, no. 1-4, pp. 213-226, 2016.

[7] H. Li, Y. Ji, G. Luo, and M. Shanghua, "A modular structure data modeling method for generalized products," International Journal of Advanced Manufacturing Technology, vol. 84, no. 1-4, pp. 197-212, 2016.

[8] S. Wang, Y. C. Liang, W. D. Li, and X. T. Cai, "Big Data enabled Intelligent Immune System for energy efficient manufacturing management," Journal of Cleaner Production, vol. 195, pp. 507-520, 2018.

[9] T. Tsuda, S. Inoue, A. Kayahara et al., "Advanced semiconductor manufacturing using big data," IEEE Transactions on Semiconductor Manufacturing, vol. 28, no. 3, pp. 229-235, 2015.

[10] R. Dubey, A. Gunasekaran, S. J. Childe, F. W. Samuel, and P. Thanos, "The impact of big data on world-class sustainable manufacturing," International Journal of Advanced Manufacturing Technology, vol. 84, no. 1-4, pp. 631-645, 2016.

[11] Z. Liu, Y. Wang, L. Cai, C. Qiang, and Z. Haiming, "Design and manufacturing model of customized hydrostatic bearing system based on cloud and big data technology," International Journal of Advanced Manufacturing Technology, vol. 84, no. 14, pp. 261-273, 2016.

[12] C. F. Chien, C. W. Liu, and S. C. Chuang, "Analysing semiconductor manufacturing big data for root cause detection of excursion for yield enhancement," International Journal of Production Research, vol. 55, pp. 1-13, 2015.

[13] A. Gunasekaran, Y. Y. Yusuf, E. O. Adeleye, and T. Papadopoulos, "Agile manufacturing practices: the role of big data and business analytics with multiple case studies," International Journal of Production Research, vol. 56, pp. 1-13, 2017.

[14] X. Li, J. Song, and B. Huang, "A scientific workflow management system architecture and its scheduling based on cloud service platform for manufacturing big data analytics," International Journal of Advanced Manufacturing Technology, vol. 84, no. 1-4, pp. 119-131, 2016.

[15] F. Tao, L. Zhang, A. Y. C. Nee, and P. Stefan Wolfgang, "Editorial for the special issue on big data and cloud technology for manufacturing," International Journal of Advanced Manufacturing Technology, vol. 84, no. 1-4, pp. 1-3, 2016.

[16] J. S. Srai, M. Kumar, G. Graham, and P. Wendy, "Distributed manufacturing: scope, challenges and opportunities," International Journal of Production Research, vol. 54, pp. 1-19, 2016.

[17] K. F. Xylogiannopoulos, P. Karampelas, and R. Alhajj, "Repeated patterns detection in big data using classification and parallelism on LERP Reduced Suffix Arrays," Applied Intelligence, vol. 45, no. 3, pp. 1-31, 2016.
[18] R. Y. Zhonga, G. Q. Huang, S. Lan, Q. Y. Dai, C. Xu, and T. Zhang, "A big data approach for logistics trajectory discovery from RFID-enabled production data," International Journal of Production Economics, vol. 165, pp. 260-272, 2015.

[19] G. Köksal, İ. Batmaz, and M. C. Testik, "A review of data mining applications for quality improvement in manufacturing industry," Expert Systems with Applications, vol. 38, no. 10, pp. 13448-13467, 2011.

[20] D. Bonilla, A. Akisawa, and T. Kashiwagi, "Modelling the adoption of industrial cogeneration in Japan using manufacturing plant survey data," Energy Policy, vol. 31, no. 9, pp. 895-910, 2003.

[21] J. Yang, S. Han, H. Kang, and J. Kim, "Product data quality assurance for e-manufacturing in the automotive industry," International Journal of Computer Integrated Manufacturing, vol. 19, no. 2, pp. 136-147, 2006. 